\title{
Functional and aesthetic outcomes of spreader graft and auto-spreader flap after nasal hump removal
}

\author{
Maged Baher Naguib, Mohamed Rifaat Ahmedº, Yasser Taha Madian, Tarek Mohamady Elnahriry and \\ Wael Elshahat Eldeeb
}

\begin{abstract}
Background: Following the reduction of the nasal hump to a desired level, spreader grafts are usually positioned to prevent the complication of nasal valve collapse. Auto-spreader flap is a new technique that gained more popularity recently and can be used as an alternative to spreader graft. This RCCT compared between both techniques aesthetically and functionally as well as the operative time.

Results: Forty patients, 17 males (42.5\%) and 23 females (57.5\%), were included. The mean duration of operation in auto-spreader flap was $11.8 \pm 3.4 \mathrm{~min}$, while it was $19.2 \pm 3.2 \mathrm{~min}$ in spreader graft. The difference between the two procedures was statistically significant $(P<0.05)$. Functional assessment of nasal obstruction was done for all patients in both groups preoperative that was $(75.6 \pm 19.9)$ which showed marked improvement when re-evaluated 3 moths postoperatively $(18.9 \pm 14.7)$, and after 6 months NOSE scale was $(29.1 \pm 20.2)$. The overall aesthetic satisfaction was $62.5 \%$ ( 25 of 40 ) irrespective of the surgery done. Sixteen out of 20 patients in spreader group and 9 out of 20 in auto-spreader flap group.

Conclusion: Auto-spreader flap and spreader graft are very effective surgical procedure for treatment of nasal obstruction due to internal nasal valve dysfunction, but the auto-spreader flap had shorter operative time. However, spreader graft has a superior aesthetic outcome.
\end{abstract}

Keywords: Rhinoplasty, Nasal valve, Obstruction, Spreader graft, Auto-spreader flap

\section{Background}

A humpy nose is among the main reasons for rhinoplasty. Removal of the hump usually leaves a flat and open roof, causing weakness of tissues at the junction of septal dorsum and upper lateral cartilage, and compromises the nasal valve angle [1]. Following the reduction of the nasal hump to a desired level, spreader grafts are usually positioned to prevent the complication of nasal valve collapse. The placement of two parallel cartilaginous spreader grafts alongside the nasal dorsum has been reported to prevent this problem [2]. In addition, they

\footnotetext{
* Correspondence: $m$ rifaat@hotmail.com

Department of Otolaryngology, Faculty of Medicine, Suez Canal University, Ismailia, Egypt

\section{Springer Open

restore the dorsal aesthetic eyebrow-nasal lines of the nasal dorsum [3].

Auto-spreader flap is a new technique that gained more popularity recently and can be used as an alternative to spreader graft [4-7]. It is less invasive as the upper lateral cartilage is rolled on itself to form its own flap as described by Fomon [8] and developed later by Gruber [5]. This technique avoids harvesting and carving cartilage for grafting from other locations. This technique is limited in cases of deviated dorsal septum and asymmetric dorsal aesthetic lines $[5,9]$.

This RCCT compared between both techniques aesthetically and functionally as well as the operative time. 


\section{Methods}

A prospective randomized controlled clinical trial (RCCT) was conducted in the period from September 2015 to September 2019. Patients attending with nasal obstruction due to nasal valve stenosis, middle vault collapse, and unhappy of the shape of their nose due to nasal hump were included in our study.

While patients with deviated dorsal septum, asymmetric dorsal aesthetic lines (both are limitations for the auto-spreader flap), patients for cosmetic complain only without nasal obstruction, hypertrophied inferior turbinates, chronic rhino sinusitis, and nasal polyposis were excluded from our study.

Patients were subjected to

- Complete history taking

- Symptoms of nasal obstruction, discharge, smell disorder, headache

- Complete ENT examination

- Nasal endoscopic examination

- Investigations including blood picture

- Radiological data: computed tomography PNS

Patients were randomly allocated into two groups:

Group (A): 20 patients were subjected for open approach rhinoplasty for hump removal with spreader grafts.

Group (B): 20 patients were subjected for open approach rhinoplasty for hump removal with autospreader flaps.

Randomization based on a consecutive basis as odd numbers were grouped into group (A) while even numbers were grouped into group (B).

\section{Surgical technique}

All surgeries were done by one team with general anesthesia and infiltration with lidocaine $(0.5 \%)$ and epinephrine $(1: 200,000)$ which was done at least $10 \mathrm{~min}$ prior to the incision to allow for adequate vasoconstriction. Generally, the lower nose and septum were injected with the vasoconstrictors at this time. Marking of the planned incision in the columella with a fine marker prior to injecting it was done. Inverted V-incision was done in the middle of columella. Then marginal or rim incision for exposure of the lower lateral cartilage. Then the mucosa was incised. Great care was taken to avoid violation of the cartilage itself.

\section{The spreader grafts}

The spreader grafts were harvested from septal cartilage according to the original technique described by Sheen [10]. They were shaped in rectangular bars, approximately $2-3 \mathrm{~cm}$ long, $3-5 \mathrm{~mm}$ wide, and $1.5 \mathrm{~mm}$ thick [2].
In case of inadequate septal cartilage due to previous septal surgery or rhinoplasty, auricular conchal cartilage was used for spreader grafts [11] and in rare cases we can use costal rib cartilage graft.

The next step of the nasal dorsum reconstruction was positioning of the harvested cartilages between the upper lateral cartilages (ULC) and the upper part of septal cartilage on both sides.

The grafts were fixed to the septal edge at least twice; adjacent to the keystone area cranially and at the anterior septal angle caudally using 5-0 polydioxanone (PDS) sutures as shown in Figs. 1 and 2.

\section{The auto-spreader flap}

After incision and cartilage exposure as mentioned for the spreader graft before, the following steps were done with no need for harvesting a graft: shown in Figs. 3 and 4

- Dissection of the mucosa from the upper lateral cartilage (ULC)

- Intercartilaginous incision along the caudal edge of the ULC

- The mucosa was dissected from the medial side of the ULC and from the corresponding septal cartilage

- ULC was folded inwards towards the septum

- Fixation of the ULC by mattress sutures

Adhesive tape was applied to the nose. Then external nasal splints were applied to provide more support.

\section{Postoperative evaluation}

The patients were observed for any postoperative bleeding and discharged after 2 days after removal of the nasal packing, if present.

Routine follow up were made monthly for 6 months postoperative with report of NOSE scale score or any complications. Evaluation of nasal obstruction was repeated at three and six months postoperative as that of preoperative evaluation.

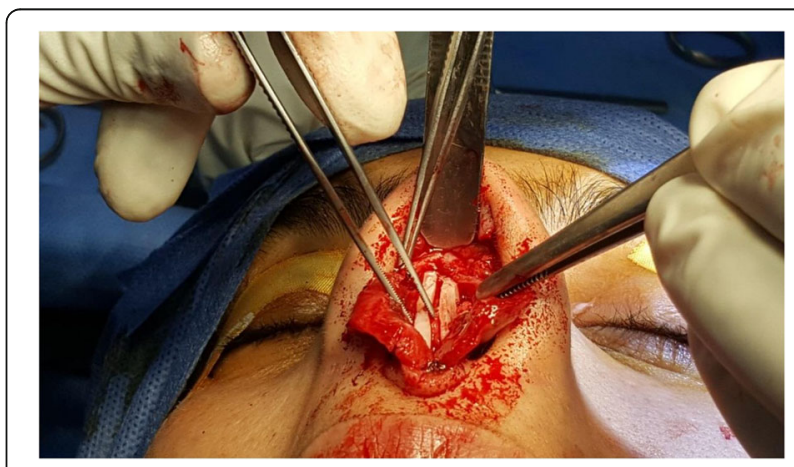

Fig. 1 Positioning of a bilateral spreader graft 


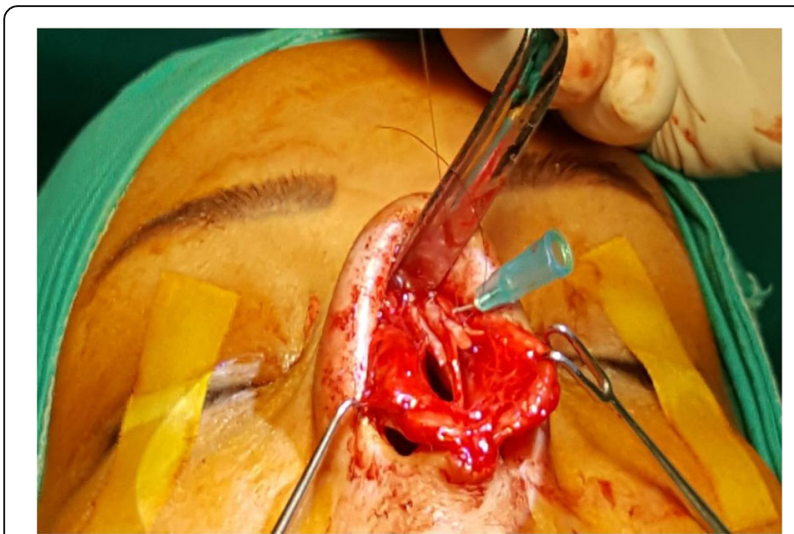

Fig. 2 Fixation of a spreader graft by PDS sutures

\section{Statistical analysis}

The data were analyzed by the SPSS software. Data were expressed as means, standard deviations (SD), minimum and maximum for the numerical analysis; correlation between two variables was done using correlation coefficient test. Comparison between two groups was done using student's $t$ test. Comparison of multiple groups was done using analysis of variance (ANOVA test) to calculate significant difference.

\section{Ethics considerations}

The local ethics committee approved the study.

Written consent was obtained from all study participants.

All participants included in the study have been informed about the procedures to be done and the expected results.

All participants agreed for the study with written informed consent obtained from them.
Written consent for study publication was obtained from all study participants.

\section{Results}

Forty patients, 17 males (42.5\%) and 23 females (57.5\%), complaining from persistent nasal obstruction and unsatisfaction of the shape of their nose were included in our study with mean age was $32.7 \pm 7.4$ years.

Regarding the operative time, the auto-spreader flap was shorter in operative time in comparison to the spreader graft. The mean duration of operation in auto-spreader flap was $11.8 \pm 3.4 \mathrm{~min}$, while it was $19.2 \pm 3.2 \mathrm{~min}$ in spreader graft. The difference between the two procedures was statistically significant $(P<0.05)$ (Table 1$)$.

Functional assessment of nasal obstruction was done for all patients in both groups preoperative that was (75.6 \pm 19.9$)$ which showed marked improvement when re-evaluated 3 moths postoperatively $(18.9 \pm 14.7)$, and after 6 months NOSE scale was $(29.1 \pm 20.2)$.

According to the line of treatment, there was a great improvement in the patients' symptom of nasal obstruction according to NOSE scale either treated by spreader graft or auto-spreader flap as shown in Table 2. As shown in Fig. 5, despite this improvement of nasal obstruction, it was statistically insignificant either after 3 or 6 months postoperative $(P>0.05)$.

The overall aesthetic satisfaction was $62.5 \%$ (25 of 40) irrespective of the surgery done, but according to the surgical procedure, it was found that $80 \%$ of patients $(16$ of 20) treated by spreader graft (group A) were satisfied, and $15 \%$ (3 of 20) reported mild improvement. Only one case $(5 \%)$ was reported with unsatisfactory aesthetic outcomes.

In group (B) where our patients were treated by autospreader flap, $45 \%$ of patients (9 of 20) were satisfied, $30 \%$ (6 of 20) mild improvement, and 25\% (5 of 20)
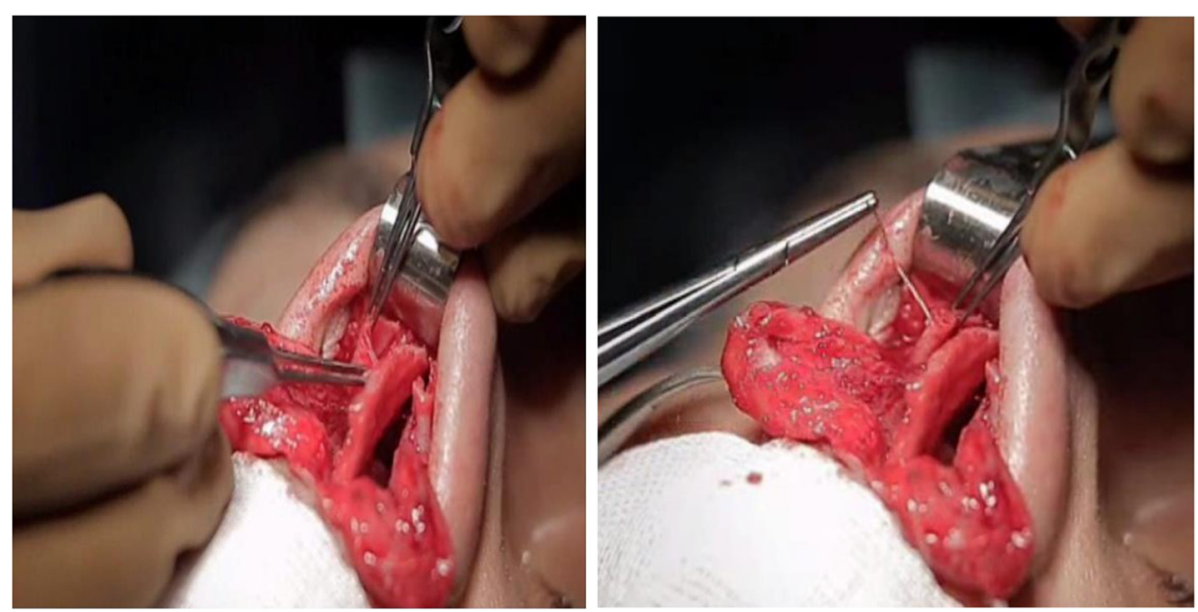

Fig. 3 Folding of the ULC inwards toward the septum in auto-spreader flap 

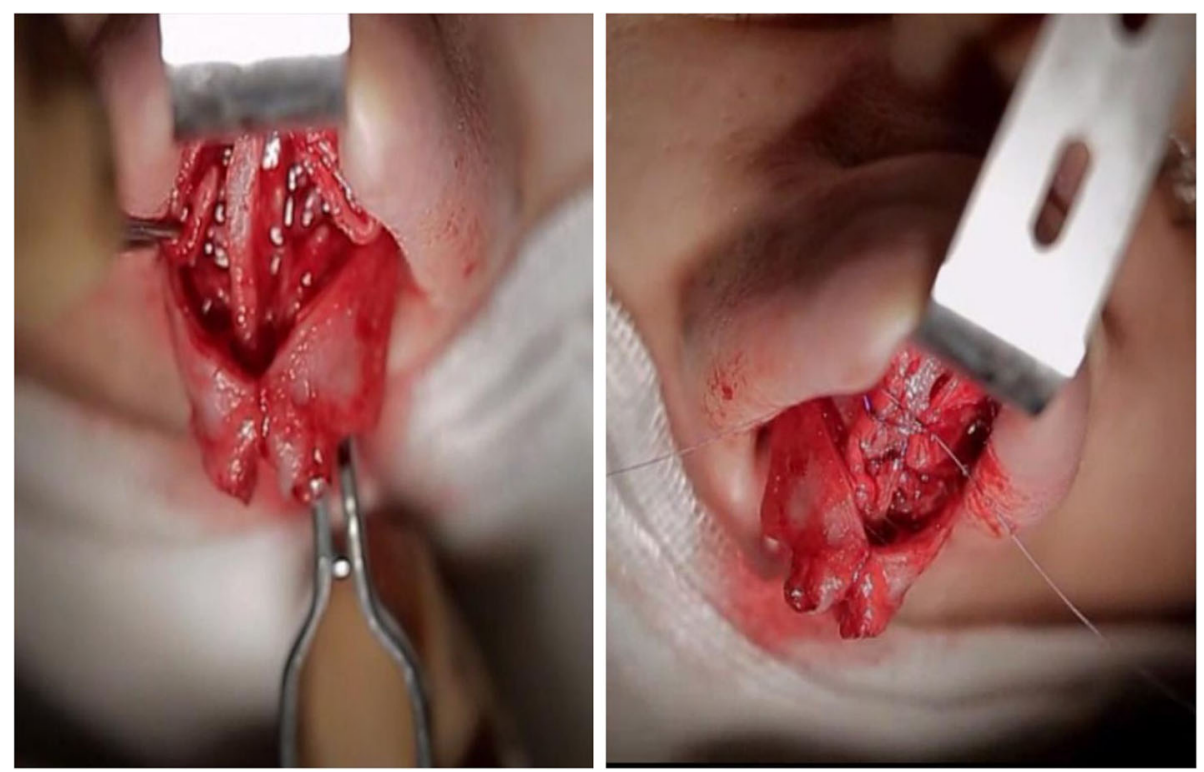

Fig. 4 Fixation of the folded ULC with a mattress suture in auto-spreader flap

experienced unsatisfactory results. The difference between two groups was statistically significant $(P<0.05)$ (Table 2; Fig. 5)

\section{Discussion}

One of the most common symptoms in otolaryngology is nasal obstruction and up to $13 \%$ are caused by internal nasal valve dysfunction. The aim to correct the internal nasal valve surgically is to widen the nasal valve angle and/or prevent it from collapse or narrowing during inspiration [10-12].

Recently, auto-spreader flaps can be commonly used as an alternative to the gold standard technique, spreader grafts, as a surgical treatment of internal nasal valve dysfunction [13]. The effectiveness of both surgical procedures is compared in this study as a randomized controlled clinical trial.

Regarding the mean operative time in this study, it was much less for auto-spreader flap than the mean time for spreader grafts (11.8 and $19.2 \mathrm{~min}$, respectively).

Same result was also reported by other studies $[6,14$, $15]$ regarding longer operative time for spreader grafts.

Table 1 Duration of operations conducted in this study

\begin{tabular}{llll}
\hline Type of surgery & \multicolumn{3}{l}{ Operative time $(\boldsymbol{m i n})$} \\
\cline { 2 - 4 } & Mean \pm SD & Min & Max \\
\hline Auto-spreader flap & $11.8 \pm 3.4$ & 7 & 17 \\
Spreader graft & $19.2 \pm 3.2$ & 15 & 26 \\
\hline
\end{tabular}

The longer operative time for spreader grafts results from the time spent for harvesting, shaping, and precise dissection in the subperichondrial plane for proper insertion of the graft $[2,16]$. However, despite longer operative time, it has the advantage of precise positing and secure insertion of the graft [16].

In addition, there are disadvantages of spreader grafts such as dropping of the graft into the mucoperichondrial pocket and displacement of the graft. Also, it is a time wasting procedure [17]. These results were supported by Gruber et al. [14] and Byrd et al. [6] regarding morbidity of donor site as well as increased operative time.

The auto-spreader graft, on the other hand, is a new technique in which the upper lateral cartilage is used as a graft where it is rolled on itself that results in less time of surgery [18]. Oneal and Berkowitz [7] were the first to describe the upper lateral cartilages as spreader grafts and later this maneuver was referred as an "auto-spreader flap" [14]. In this technique, no need of harvesting cartilage septal graft that shortens the operative time $[7,19]$. In addition, it will save the patient from unnecessary morbidity and obviate the need of harvesting ear cartilage in cases of

Table 2 Patients satisfaction among spreader graft and autospreader flap groups

\begin{tabular}{lllll}
\hline Type of surgery & \multicolumn{3}{l}{ Aesthetic satisfaction } & N \\
\cline { 2 - 4 } & Satisfactory & Mild & Unsatisfactory & \\
\hline Spreader graft & 16 & 3 & 1 & 20 \\
Auto-spreader Flap & 9 & 6 & 5 & 20 \\
Total & 25 & 9 & 6 & 40 \\
\hline
\end{tabular}




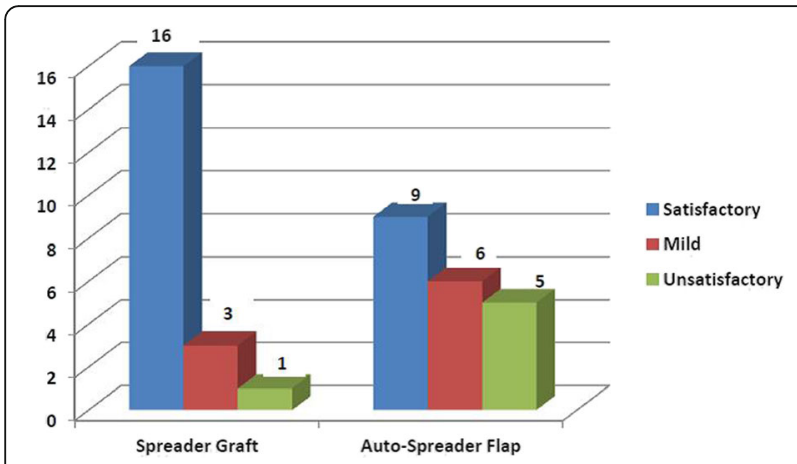

Fig. 5 Statistical significance of NOSE scale in both groups

previous septal surgery where no adequate septal cartilage is available [9].

The Nasal Obstruction Symptom Evaluation (NOSE) scale is validated in 2004 , as a convenient, efficient, simple, and disease-specific quality of life (QOL) instrument designed for assessment of nasal obstruction [20-22]. Lam. et al. [23] mentioned that quantitative measures as acoustic rhinometry do not necessarily correlate with the patient's symptoms. Then, NOSE scale score has confirmed by Lipan and Most [24] as an effective tool for subjective assessment of postoperative nasal obstruction.

In Standlee and Hohman's [25] study, they reported reduction in NOSE scores by an average of 46 points postoperatively. Our study showed that the mean eduction of NOSE score in this study for patients treated by spreader grafts was more than 43 and 36 points after 3 and 6 months postoperative respectively which is almost consistent with Standlee and Homan [25] regarding the improvement of NOSE score postoperatively irrespective of the surgical procedure in comparison with the preoperative mean NOSE score.

Rhee et al. [26] compared multiple studies [27-32] by using the mean NOSE improvement after surgery and they found that it was more than 40 points. In addition, Standlee and Hohman [25] found that spreader grafts in rhinoplasty results in great improvement in NOSE score and subjective sensation of nasal obstruction.

According to our study, there was decrease in NOSE score either 3 or 6 months after surgery either done by spreader graft or auto-spreader flap. Our results agreed with Sowder et al. [13] who reported the same outcomes.

Aesthetic outcomes in this study revealed that 6 patients out of $40(15 \%)$ experienced unsatisfactory results irrespective of the procedure. There is only one patient (5\%) who reported unsatisfactory result with spreader graft and 5 patients (25\%) with auto-spreader flap.

Our aesthetic results are comparable to previous studies that reported aesthetic outcomes. Salyer [27] analyzed 101 primary cosmetic rhinoplasty and he found that $16 \%$ were unhappy from their aesthetic outcome. In addition, Hassanpour et al. [33] compared the aesthetic and functional outcomes of spreader grafts and autospreader flaps and reported that $14 \%$ of their subjects were unsatisfied on aesthetic outcomes.

Saedi et al. [29] found that the auto-spreader flap in primary rhinoplasty was an effective technique in preservation of the middle nasal vault. However, the autospreader flap was not able to provide adequate dorsal width compared with spreader graft. In addition, the auto-spreader flap cannot be used in some cases such as minimal dorsal humps, crocked nose, and secondary cases [33]. Another disadvantage of the auto-spreader flap is its inability to be extended down to the anterior septal angle so the lower third of dorsum cannot be addressed [30].

\section{Conclusion}

Both spreader grafts and auto-spreader flaps are very effective in the treatment of nasal valve collapse. However, the auto-spreader flap has shorter operative time in comparison to the spreader graft. The difference was highly statistically significant.

\section{Abbreviations \\ NOSE scale: Nasal obstruction and septoplasty effectiveness scale; RCCT: Randomized controlled clinical trial; ULC: Upper lateral cartilages; PDS: Polydioxanone; SD: Standard deviations}

\section{Acknowledgements \\ None.}

\section{Authors' contributions}

$\mathrm{MB}$ analyzed and interpreted the patient data regarding radiological evaluation, MR follow up patients and collect the patient's data, YT analyzed the statistical sections and photography patients pre- and postoperative, TM performed the surgical interventions, and WE was a major contributor in writing the manuscript. The authors read and approved the final manuscript.

Funding

None.

Availability of data and materials

Not applicable.

Ethics approval and consent to participate

Local ethics committee (Faculty of Medicine Suez Canal University under the number 333 - September 2015).

\section{Consent to participate}

Written consent was obtained from all study participants and all participants included in the study have been informed about the procedures to be done and the expected results.

\section{Consent for publication}

Written Consent for study publication was obtained from all study participants.

Competing interests

The authors declare that they have no competing interests. 
Received: 2 July 2020 Accepted: 10 November 2020

Published online: 01 December 2020

\section{References}

1. Teymoortash A, Fasunla JA, Sazgar A (2012) The value of spreader grafts in rhinoplasty: a critical review. Eur Arch Otorhinolaryngol 269(5):1411-1416

2. Sheen JH (1984) Spreader graft: a method of reconstructing the roof of the middle nasal vault following rhinoplasty. Plast Reconstr Surg 73(2):230-239

3. Jin HR, Won TB (2007) Nasal hump removal in Asians. Acta Otolaryngol Suppl 558:95-101

4. Bessler S, Kim Haemmig H, Schuknecht B, Meuli-Simmen C, Strub B (2015) Anterior spreader flap technique: a new minimally invasive method for stabilizing and widening the nasal valve. J Plast Reconstr Aesthet Surg 68(12):1687-1693

5. Gruber RP, Park E, Newman J, Berkowitz L, Oneal R (2007) The spreader flap in primary rhinoplasty. Plast Reconstr Surg 119(6):1903-1910

6. Byrd HS, Meade RA, Gonyon DL (2007) Using the autospreader flap in primary rhinoplasty. Plast Reconstr Surg 119:1897-1902

7. Oneal RM, Berkowitz RL (1998) Upper lateral cartilage spreader flaps in rhinoplasty. Aesthet Surg J 18:370-371

8. Fomon S, Caron A (1950) Collapsed ala. Acta Otolaryngol 51:465-484

9. Yoo S, Most SP (2011) Nasal airway preservation using the autospreader technique. Analysis of outcomes using a disease-specific quality of life instruments. Arch Facial Plast Surg 13(4):231-233

10. Helal MZ, El-Tarabishi M, Magdy Sabry S, Yassin A, Rabie A, Lin SJ (2010) Effects of rhinoplasty on the internal nasal valve: a comparison between internal continuous and external perforating osteotomy. Ann Plast Surg 64(5):649-657

11. Schlosser RJ, Park SS (1999) Functional rhinoplasty. Operative techniques in otolaryngology. Head Neck Surg 10(3):203-208

12. Elwany S, Thabet H (1996) Obstruction of the nasal valve. J Laryngol Otol 110(3):221-224

13. Sowder JC, Thomas AJ, Gonzalez CD, Limaye NS, Ward PD (2017) Use of spreader flaps without dorsal hump reduction and the effect on nasal function. JAMA Facial Plast Surg 19(4):287-292

14. Gruber RP, Melkun ET, Woodward JF, Perkins SW (2011) Dorsal reduction and spreader flaps. Aesthet Surg J 31(4):456-464

15. Kutubidze A (2015) Nasal dorsal aesthetic lines and rhinoplasty technical tricks. Review article. Plast Aesthet Res 2:315-319

16. Andre RF, Paun SH, Vuyk HD (2004) Endonasal spreader graft placement as treatment for internal nasal valve insufficiency: no need to divide the upper lateral cartilages from the septum. Arch Facial Plast Surg 6(1):36-40

17. Rohrich RJ, Ghavami A (2009) Rhinoplasty for middle eastern noses. Plast Reconstr Surg 123:1343-1354

18. Zojaji R, Keshavarzmanesh M, Arshadi HR, Mazloum Farsi Baf M, Esmaeelzadeh S (2014) Quality of life in patients who underwent rhinoplasty. Facial Plast Surg 30:593-596

19. Lerma J (1998) The "lapel" technique. Plast Reconstr Surg 102(6):2274-2275

20. Stewart MG, Witsell DL, Smith TL, Weaver EM, Yueh B, Hannley MT (2004) Development and validation of the nasal obstruction symptom evaluation (NOSE) scale. Otolaryngol Head Neck Surg 130(2):157-163

21. Stewart MG, Smith TL, Weaver EM et al (2004) Outcomes after nasal septoplasty: results from the nasal obstruction Septoplasty effectiveness (NOSE) study. Otolaryngol Head Neck Surg 130(3):283-290

22. Most SP (2006) Analysis of outcomes after functional rhinoplasty using a disease-specific quality-of-life instrument. Arch Facial Plast Surg 8(5):306-309

23. Lam DJ, James KT. Weaver EM (2006) Comparison of anatomic physiological, and subjective measures of the nasal airway. Am J Rhinol 20(5):463-470

24. Lipan MJ, Most SP (2013) Development of a severity classification system for subjective nasal obstruction. JAMA Facial Plast Surg 15(5):358-361

25. Standlee AG, Hohman MH (2017) Evaluating the effect of spreader grafting on nasal obstruction using the nose scale. Ann Otol Rhinol Laryngol 126(3): 219-223

26. Rhee JS, Sullivan CD, Frank DO, Kimbell JS, Garcia GJM (2014) A systematic review of patient-reported nasal obstruction scores. JAMA Facial Plast Surg 16(3):219-225

27. Salyer KE (1986) Primary correction of the unilateral cleft lip nose: a 15-year experience. Plast Reconstr Surg 77:558-566
28. Varedi P, Bohluli B, Bayat M, Mohammadi F (2014) Spreader graft placement: a simplified technique for young surgeons. Int J Oral Maxillofac Surg 43: 1216-1217

29. Saedi B, Amali A, Gharavis V, Yekta BG, Most SP (2014) Spreader flaps do not change early functional outcomes in reduction rhinoplasty: a randomized control trial. Am J Rhinol Allergy 28:70-74

30. Manavbaşı YI, Başaran I (2011) The role of upper lateral cartilage in dorsal reconstruction after hump excision: section 1. Spreader flap modification with asymmetric mattress suture and extension of the spreading effect by cartilage graft. Aesthetic Plast Surg 35:487-493

31. Egan KK, Kim DW (2005) A novel intranasl stent for functional rhinoplasty and nostril stenosis. Laryngoscope. 115(5):903-909

32. Most SP (2006) Anterior septal reconstruction: outcomes after a modified extracorporeal septoplasty technique. Arch Facial Plast Surg 8(3):202-207

33. Hassanpour SE, Heidari A, Moosavizadeh SM, Tarahomi MR, Goljanian A, Tavakoli S (2016) Comparison of aesthetic and functional outcomes of spreader graft and autospreader flap in rhinoplasty. World J Plast Surg 5(2): $133-138$

\section{Publisher's Note}

Springer Nature remains neutral with regard to jurisdictional claims in published maps and institutional affiliations.

\section{Submit your manuscript to a SpringerOpen ${ }^{\circ}$ journal and benefit from:}

- Convenient online submission

- Rigorous peer review

- Open access: articles freely available online

High visibility within the field

- Retaining the copyright to your article

Submit your next manuscript at $>$ springeropen.com 